in vivo $32: 1403-1408(2018)$

doi:10.21873/invivo.11392

\title{
Change in Amino Acid Pools During Neuronal Differentiation of PC12 Cells
}

\author{
AIKO SANO ${ }^{1}$, HAIXIA SHI ${ }^{2,3}$, RYUICHIRO SUZUKI $^{1}$, YOSHIAKI SHIRATAKI $^{1}$ and HIROSHI SAKAGAMI ${ }^{3}$ \\ ${ }^{1}$ Faculty of Pharmacy and Pharmaceutical Sciences, Josai University, Saitama, Japan; \\ ${ }^{2}$ Department of Traditional Chinese Medicine, Shanghai Ninth People's Hospital, \\ Shanghai Jiatong University School of Medicine, Shanghai, P.R. China; \\ ${ }^{3}$ Meikai University Research Institute of Odontology (M-RIO), \\ Meikai University School of Dentistry, Saitama, Japan
}

\begin{abstract}
Background/Aim: Although rat PC12 cells are a well-established model to investigate neuronal differentiation, survival and function, the reports of differentiation-associated changes in the intracellular amino acid pools of neurotransmitters have been limited. In this study, possible changes in the intracellular amino acid pools were investigated during nerve growth factor (NGF)-induced differentiation of PC12 cells. Materials and Methods: Rat PC12 cells were induced to differentiate into neuronal cells by $50 \mathrm{ng} / \mathrm{ml} \mathrm{NGF}$ in serum-free Dulbecco's Modified Eagle's medium, followed by the addition of fresh NGF-containing medium at day 3, without medium change. Cell viability was determined by the 3-(4,5dimethylthiazol-2-yl)-2,5-diphenyltetrazolium bromide (MTT) method. Intracellular amino acids were extracted by 5\%trichloroacetic acid and quantified by amino acid analyzer. Results: Differentiated PC12 cells showed high concentrations of excitatory neurotransmitters (glutamic acid and aspartic acid) and glutamine (energy supply). In contrast, urea and taurine levels declined with the progression of neuronal differentiation. Exogenous addition of taurine, urea, and $L$ - and D-aspartic acid showed little or no effect on supporting viability of PC12 cells cultured in serum-free medium. Conclusion: The present study demonstrated dramatic changes in the composition of intracellular amino acids during neuronal differentiation.
\end{abstract}

This article is freely accessible online.

Correspondence to: Ryuichiro Suzuki, Faculty of Pharmacy and Pharmaceutical Sciences, Josai University, Sakado, Saitama, 3500295, Japan. Tel/Fax: +81 492718089, e-mail: ryu_suzu@josai.ac.jp and Hiroshi Sakagami, Meikai University Research Institute of Odontology (M-RIO), Meikai University School of Dentistry, Sakado, Saitama 350-0283, Japan. Tel: +81 492792758, Fax: +81 492855171, e-mail: sakagami@dent.meikai.ac.jp

Key Words: Neuronal differentiation, PC12 cells, NGF, amino acid concentration, urea, taurine, aspartic acid, overlay isolation method.
Rat PC12 pheochromocytoma cells (1) have been used for searching for neurotrophic natural products (2), and neurotrophic signaling pathways induced by pituitary adenylate cyclaseactivating polypeptide (3), nerve growth factor (NGF), brain derived neurotrophic factor (BDNF) and neurotrophins NT-3 and NT-4 (4), precursor of NGF (5), and polyphenols (6).

Glutamate (7) and hydroxydopamine (8) are well known to induce cytotoxicity against PC12 cells, whereas taurine (9, $10)$ and urea $(11,12)$ are neuroprotective. We have recently reported that the sensitivity of PC12 cells against eight anticancer drugs generally declined during NGF-induced neuronal differentiation (13). In addition, we have recently developed a simplified method for collecting large amounts of neuronal cells removing collagen-coating step (14). Using this method, the possible change in intracellular amino acid pools during NGF-induced neuronal differentiation of PC12 cells were investigated.

\section{Materials and Methods}

Materials. The following chemicals and reagents were obtained from the indicated companies: Dulbecco's modified Eagle's medium (DMEM), taurine, L-aspartic acid, D-aspartic acid, urea, human recombinant NGF, trichloroacetic acid (TCA) and dimethyl sulfoxide (DMSO) from FUJIFILM Wako Pure Chemical Co. (Osaka, Japan); fetal bovine serum (FBS), 3-(4,5-dimethylthiazol2-yl)-2,5-diphenyltetrazolium bromide (MTT), from Sigma-Aldrich Inc. (St. Louis, MO, USA); 96-microwell plates (TPP) from Techno Plastic Products AG (Trasadingen, Switzerland).

Cell culture. PC12, a cell line derived from a pheochromocytoma of rat adrenal medulla (1), purchased from Riken Cell Bank (Tsukuba, Japan), was cultured in DMEM supplemented with $10 \%$ heat-inactivated FBS, 100 units/ml, penicillin G and $100 \mu \mathrm{g} / \mathrm{ml}$ streptomycin under a humidified $5 \% \mathrm{CO}_{2}$ atmosphere.

Induction of differentiation toward neurons. PC12 cells were inoculated at $3 \times 10^{3}$ cells per microwell $\left(0.32 \mathrm{~cm}^{2}\right)$ and incubated for $24 \mathrm{~h}$ to allow complete cell attachment. The medium was completely removed by 

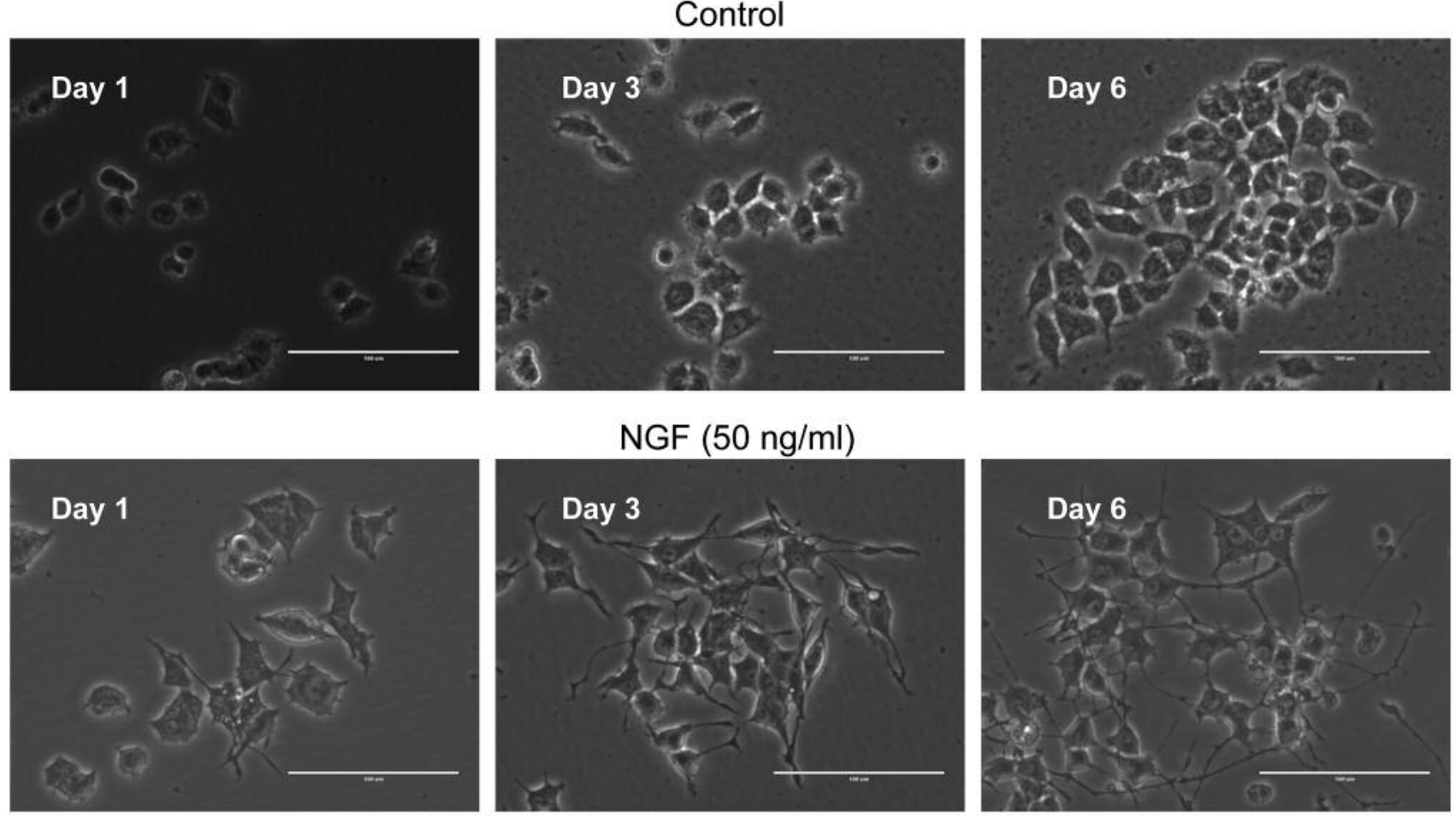

Figure 1. Induction of neuronal differentiation by NGF. PC12 cells were inoculated at $2 \times 10^{3}$ cells per microwell $\left(0.32 \mathrm{~cm}^{2}\right)$, and incubated for $48 \mathrm{~h}$ to allow complete cell attachment. Cells were then treated for 0 (day 0 ) or 3 days (day 3) with $50 \mathrm{ng} / \mathrm{ml} \mathrm{NGF}$. At day 3 , culture media were supplemented by overlay with fresh NGF solution and incubated for another 3 days (day 6). Bar=100 $\mu m$.

suction and replaced with $0.1 \mathrm{ml}$ of differentiation medium (serum-free DMEM containing $50 \mathrm{ng} / \mathrm{ml} \mathrm{NGF).} \mathrm{Cells} \mathrm{were} \mathrm{then} \mathrm{incubated} \mathrm{for} 72$ $\mathrm{h}$ to induce neuronal differentiation characterized by neurite formation (referred to as day 3 cells) (14). Then, $0.1 \mathrm{ml}$ of differentiation medium were added without medium change and incubation continued for another 3 days [overlaid with $0.1 \mathrm{ml}$ of differentiation medium at day 3] (referred to as day 6 cells). Cell morphology was examined periodically under the observation by light microscopy (EVOS FL; ThermoFisher Scientific, Waltham, MA, USA).

Determination of viable cell number. The viable cell number was determined by the 3-(4,5-dimethylthiazol-2-yl)-2,5-diphenyltetrazolium bromide (MTT) method. MTT concentration was reduced from $0.2 \mathrm{mg} / \mathrm{ml}$ to $0.1 \mathrm{mg} / \mathrm{ml}$, due to its cytotoxicity towards neuronal cells. The cells were incubated for $1 \mathrm{~h}$, and the formazan precipitate was dissolved in DMSO and the absorbance at $560 \mathrm{~nm}$ was measured (that reflects the relative viable cell number, more precisely cellular mitochondrial activity) with a plate leader (Infinite F50R; TECAN, Kawasaki, Japan) (13).

Extraction of amino acids. Medium of control and treated cells was centrifuged to collect the clear supernatant without cell debris. This supernatant $(100 \mu \mathrm{l})$ was mixed with $100 \mu \mathrm{l}$ of $10 \%$ trichloroacetic acid (TCA), and placed for $10 \mathrm{~min}$ on ice. After centrifugation at $10,000 \times g$, the deproteinized supernatant was frozen at $-30^{\circ} \mathrm{C}$ prior to amino acid analysis (15).
Amino acid analysis. Amino acid analysis of the extracts was conducted on an JLC-500/V amino acid analyzer (JEOL) with two single-channel colorimeters. Detection was carried out at two wavelengths (570 and $440 \mathrm{~nm})$ according to the manufacturer's instructions. Separation was performed on an ionexchange column packed with sulfonated styrene-divinylbenzene copolymer (LCR-6, JEOL) using a stepwise gradient of Li-citrate buffers ( $1 \mathrm{st}$ to 5 th) at elution rate $0.42 \mathrm{ml} / \mathrm{min}$ and temperature gradient during chromatographic separation (the column was thermostated at the temperature interval of $30-70^{\circ} \mathrm{C}$ ). Amino acid standards (Amino Acids Mixture Standard Solution, Type H, Type AN-II, Type B was used for calibration of the instrument. On-line post-column amino acid derivatization was used for quantitative assessment of amino acids in the eluate, which occurred by mixing the eluate with ninhydrin reagent solution supplied by a separate pump. The ninhydrin reagent is comprised of special ninhydrin buffer and ninhydrin reagent (FUJIFILM Wako Pure Chemical Corporation). The stained products of derivatization were detected at $570 \mathrm{~nm}$ for all amino acids except proline and hydroxy-proline, which were recorded colorimetrically at $440 \mathrm{~nm}$.

Statistical treatment. Experimental values are expressed as the mean \pm standard deviation (SD) of six determinants. Statistical analysis was performed using Student's $t$-test. A $p$-value of less than 0.05 was considered significant. 


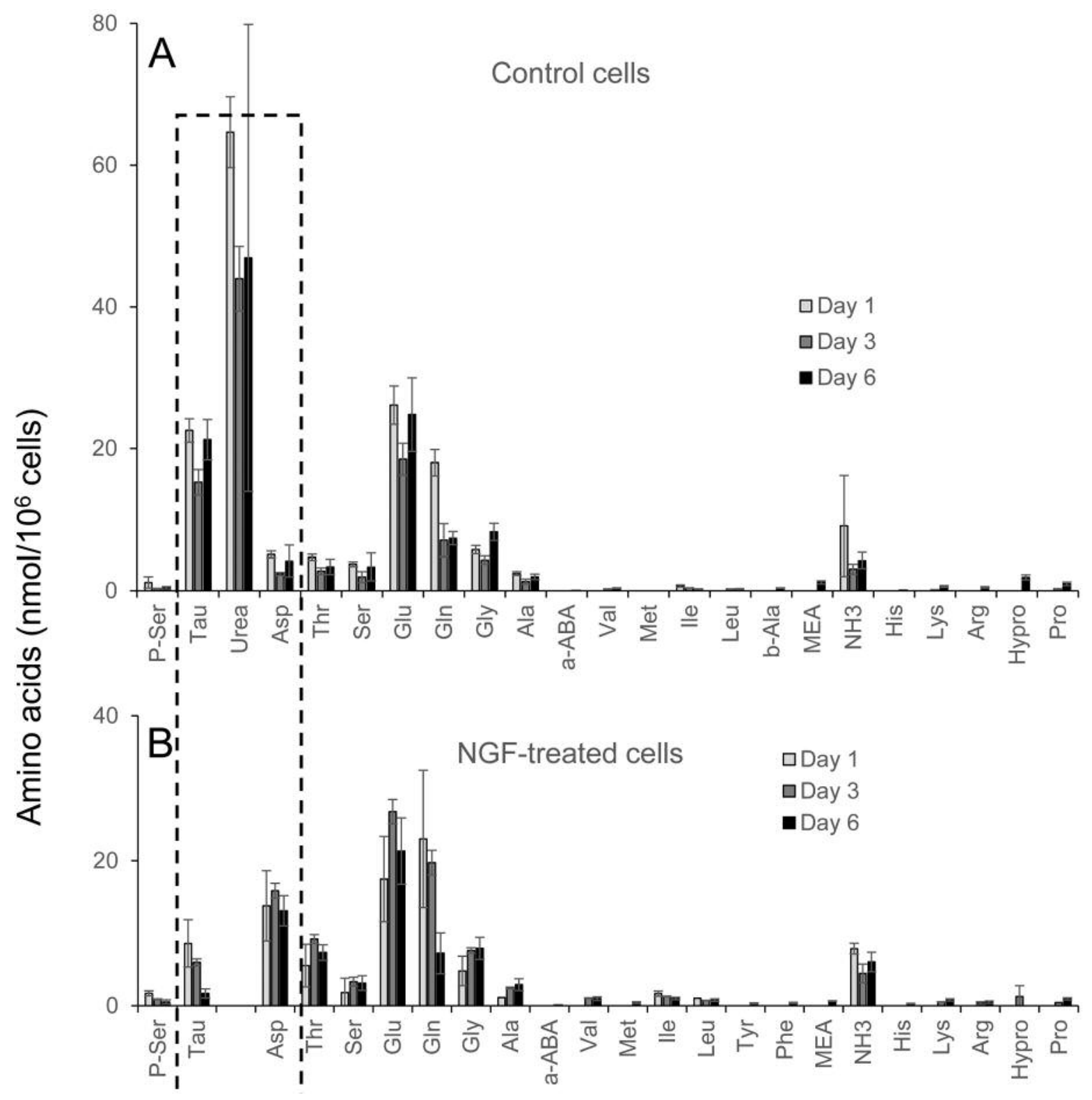

Figure 2. Changes in the intracellular concentration of amino acids during NGF-induced neuronal differentiation. Intracellular concentration of amino acids in control cells (A) and NGF-treated cells (B). PC12 cells were differentiated as described in Figure 1, and the concentrations of intracellular amino acids were determined as described in Materials and Methods. Each value represents mean \pm S.D. of quadruplicate assays.

\section{Results}

Induction of neuronal differentiation by NGF. We have recently found that FBS was needed to maintain PC12 cells, whereas it was rather inhibitory of NGF-induced differentiation of PC12 cells (14). The optimal concentration of NGF was $50 \mathrm{ng} / \mathrm{ml}$ (14). When PC12 cells were incubated for 3 and 6 days with NGF, the cells differentiated into neuronal cells characterized by neurite formation, and neurite network became more extended with the progression of differentiation (compare day 3 and day 6 in Figure 1).

Change of intracellular amino acids during neuronal differentiation. The intracellular amino acid concentration of PC12 cells was initially measured before differentiation. Amino acid analysis of TCA-soluble fraction of cell lysate demonstrated that PC12 cells contain both excitatory (glutamic acid, aspartic acid) and inhibitory amino acids (glycine) 

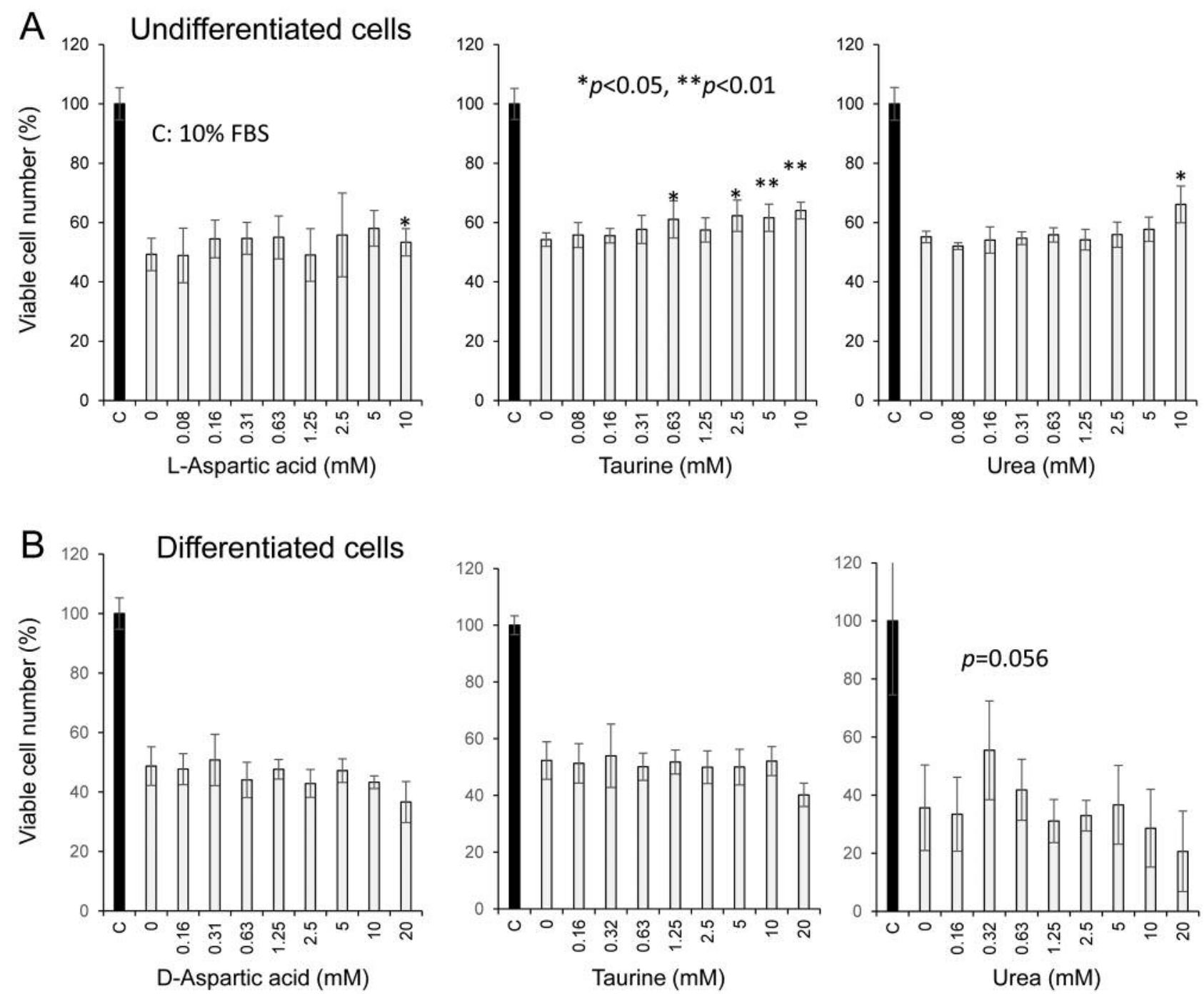

Figure 3. Effect of addition of urea, taurine or aspartic acid on cell viability. PC12 cells before (A) and after differentiation (day 6) (B) were incubated for $24 \mathrm{~h}$ in regular culture medium (indicated by $C$ ) or in serum-free DMEM supplemented with the indicated concentrations of urea, taurine, and L- or D-aspartic acid. The viability was then determined by the MTT method, and is presented as \% of control. Each value represents mean \pm S.D. of six determinants.

(Figure 2A). Among all amino acids detected, glutamic acid (mean values: $23.13 \mathrm{nmol} / 10^{6}$ cells) was the most abundant, followed by glutamine (10.80), glycine (6.09), aspartic acid (3.87), threonine (3.59), serine (2.99), hydroxyproline (1.89), alanine (1.88), proline (0.59), arginine (0.48), isoleucine $(0.42)$, lysine $(0.38)$, valine $(0.29)$, leucine $(0.25)$, histidine (0.12). It was unexpected that PC12 cells contained the highest concentration of urea (51.84), and concentration of taurine (19.68) comparable with that of glutamic acid (Figure 2A).

During differentiation, the concentration of glutamic acid remained the highest and relatively stable (mean of day 1 , day 3 and day $6=21.85 \mathrm{nmol} / 10^{6}$ cells). The concentrations of other amino acids are as follows: glutamine (16.65), aspartic acid (14.24), threonine (7.35), glycine (6.77), serine (2.74), alanine (2.12), isoleucine (1.30), valine (1.00), leucine $(0.83)$, proline $(0.67)$, lysine $(0.65)$, hydroxyproline $(0.63)$, arginine (0.42), methionine $(0.41)$, phenylalanine $(0.37)$, tyrosine (0.31), histidine (0.28). Urea became undetectable, and taurine showed time-dependent reduction: 8.58 (day 1), 5.96 (day 3) and 1.69 (day 6) (Figure 2B).

Effect of exogenous addition of urea, taurine or aspartic acid on cell viability. When undifferentiated PC12 cells were cultured for $24 \mathrm{~h}$ in serum-free DMEM, viable cells reduced 
to nearly $50 \%$ of control level. However, viability was slightly but significantly increased $(p<0.01)$ by addition of taurine and urea, but not by L-aspartic acid (Figure 3).

When differentiated PC12 cells (Day 6) were cultured for 24 $\mathrm{h}$ in serum-free DMEM, viability was also declined to $50 \%$ of control. However, growth stimulation activity was only observed at $0.32 \mathrm{mM}$ urea, but was not statistically significant $(p=0.056)$ (Figure 3B).

\section{Discussion}

It was essential to select the best culture medium for the maintenance and differentiation induction. For the maintenance of PC12 cells, we have proposed to use the simple DMEM+10\%FBS medium, since extra addition of Ham's F12 (1:1), non-essential amino acids (NEAA), horse serum (HS) did not improve, but rather reduced the growth and amino acid consumption of PC12 cells (14). For the differentiation-induction, we have proposed the use of the simple overlay method, since this method can provide large amounts of differentiated cells by removing the toxic coating step (14). Using this differentiation method (overlay), the possible changes in amino acid pools during the NGF-induced neuronal differentiation of PC12 cells were investigated.

The present study demonstrated that differentiated PC12 cells have high concentrations of glutamic acid and aspartic acid, in agreement with previous reports that these excitatory amino acids are found in high concentration in brain, and they show powerful excitatory effects on neurons of the central nervous system $(16,17)$. Since $\mathrm{D}$-aspartic acid is synthesized intracellularly, most likely by aspartate racemase(s) in PC12 cells (18), the relative ratio of L-aspartic acid and D-aspartic acid should be determined. We found that differentiated cells contained higher concentration of glutamine $\left(16.65 \mathrm{nmol} / 10^{6}\right.$ cells) than undifferentiated cells $\left(10.80 \mathrm{nmol} / 10^{6}\right.$ cells) (Figure 2 ), suggesting higher dependence of the differentiated cells on glutamine as energy donor (19).

We found that the intracellular concentration of taurine declined with the progression of neuronal differentiation (Figure 3). It has been reported that taurine shows neuroprotective effects by reducing endoplasmic reticulum stress (ER stress) caused by glutamate excitotoxicity or excessive reactive oxygen species in $\mathrm{PC} 12$ cells or rat neuronal cultures $(9,10)$. Exogenous addition of taurine and urea showed little or no effect on supporting the growth of PC12 cells regardless of the differentiation stage.

Anticancer drugs such paclitaxel (20) and oxaliplatin (21) have been reported to induce neurotoxicity in PC12 cells. It remains to be investigated whether taurine and urea show any protective activity

In conclusion, the present study demonstrated dramatic changes in the composition of intracellular amino acids during neuronal differentiation. Further study on metabolic pathways including urea cycle and mitochondrial tricarboxylic acid (TCA) cycle may reveal the biological significance of these phenomena, and the role of taurine, urea and aspartic acid as differentiation marker.

\section{Conflicts of Interest}

The Authors confirm that there are no known conflicts of interest associated with this publication and no significant financial support for this work that could have influenced its outcome.

\section{Acknowledgements}

This work was partially supported by KAKENHI from the Japan Society for the Promotion of Science (JSPS) (16K11519).

\section{References}

1 Greene LA and Tischler AS: Establishment of a noradrenergic clonal line of rat adrenal pheochromocytoma cells which respond to nerve growth factor. Proc Natl Acad Sci USA 73(7): 2424-2428, 1976.

2 Li Y and Ohizumi Y: Search for constituents with neurotrophic factor-potentiating activity from the medicinal plants of Paraguay and Thailand. Yakugaku Zasshi 124(7): 417-424, 2004.

3 Ravni A, Bourgault S, Lebon A, Chan P, Galas L, Fournier A, Vaudry H, Gonzalez B, Eiden LE and Vaudry D: The neurotrophic effects of PACAP in PC12 cells: control by multiple transduction pathways. J Neurochem 98(2): 321-329, 2006.

4 Uren RT and Turnley AM: Regulation of neurotrophin receptor (Trk) signaling: suppressor of cytokine signaling 2 (SOCS2) is a new player. Front Mol Neurosci 7: 39, 2014.

5 Bradshaw RA, Pundavela J, Biarc J, Chalkley RJ, Burlingame AL and Hondermarck H: NGF and ProNGF: Regulation of neuronal and neoplastic responses through receptor signaling. Adv Biol Regul 58: 16-27, 2015.

6 Moosavi F, Hosseini R, Saso L and Firuzi O: Modulation of neurotrophic signaling pathways by polyphenols. Drug Des Devel Ther 10: 23-42, 2015.

7 Song Q, Gou WL and Zou YL: FAM3A protects against glutamate-induced toxicity by preserving calcium homeostasis in differentiated PC12 cells. Cell Physiol Biochem 44(5): 20292041, 2017.

8 Dong RF, Zhang B, Tai LW, Liu HM, Shi FK and Liu NN: The neuroprotective role of MiR-124-3p in a 6-hydroxydopamineinduced cell model of Parkinson's Disease via the regulation of ANAX5. J Cell Biochem 119(1): 269-277, 2018.

9 Prentice H, Pan C, Gharibani PM, Ma Z, Price AL, Giraldo GS, Retz HM, Gupta A, Chen PC, Chiu H, Modi J, Menzie J, Tao R and Wu JY: Analysis of neuroprotection by taurine and taurine combinations in primary neuronal cultures and in neuronal cell lines exposed to glutamate excitotoxicity and to hypoxia/reoxygenation. Adv Exp Med Biol 975: 207-216, 2017.

10 Prentice H, Gharibani PM, Ma Z, Alexandrescu A, Genova R, Chen PC, Modi J, Menzie J, Pan C, Tao R and Wu JY: Neuroprotective functions through inhibition of ER stress by taurine or taurine combination treatments in a Rat stroke model. Adv Exp Med Biol 975: 193-205, 2017. 
11 Zassler B, Dechant G and Humpel C: Urea enhances the nerve growth factor-induced neuroprotective effect on cholinergic neurons in organotypic rat brain slices. Neuroscience 130(2): 317-323, 2005 .

12 Jęśko H, Lukiw WJ, Wilkaniec A, Cieślik M, GąssowskaDobrowolska M, Murawska E, Hilgier W and Adamczyk A: Altered expression of urea cycle enzymes in amyloid- $\beta$ protein precursor overexpressing PC12 cells and in sporadic Alzheimer's disease brain. J Alzheimers Dis 62(1): 279-291, 2018.

13 Sakagami H, Hara Y, Shi H, Iwama S, Nakagawa M, Suzuki H, Tanaka K, Abe T, Tamura N, Takeshima H, Horie N, Kaneko T, Shiratsuchi $\mathrm{H}$ and Kaneko T: Change in anticancer drug sensitivity during neuronal differentiation of PC12 cells. In Vivo 32(4): 765-770, 2018.

14 Sakagami H, Shi H, Bandow K, Tomomura M, Tomomura A, Horiuchi M, Fujisawa T and Oizumi T: Search of neuroprotective polyphenols using the "overlay" isolation method. Molecules 23: $1840,2018$.

15 Sakagami H, Suzuki R, Shirataki Y, Iwama S, Nakagawa M, Suzuki H, Tanaka K, Tamura N and Takeshima H: Re-evaluation of culture condition of PC12 and SH-SY5Y cells based on growth rate and amino acid consumption. In Vivo 31(6): 1089-1095, 2017.

16 Bleich S, Römer K, Wiltfang J and Kornhuber J: Glutamate and the glutamate receptor system: a target for drug action. Int $\mathrm{J}$ Geriatr Psychiatry 18(Suppl 1): S33-40, 2003.
17 Conn PJ: Physiological roles and therapeutic potential of metabotropic glutamate receptors. Ann NY Acad Sci 1003: 12$21,2003$.

18 Homma H: Biochemistry of D-aspartate in mammalian cells. Amino Acids 32(1): 3-11, 2007.

19 Scalise M, Pochini L, Galluccio M, Console L and Indiveri C: Glutamine transport and mitochondrial metabolism in cancer cell growth. Front Oncol 7: 306, 2017.

20 Hara Y, Sakagami H, Shi H, Abe T, Tamura N, Takeshima H, Horie $\mathrm{N}$ and Kaneko T, Shiratsuchi $\mathrm{H}$ and Kaneko T: Partial protection of paclitaxel-induced neurotoxicity by antioxidants. In Vivo 32(4): 745-752, 2018.

21 Ceresa C, Avan A, Giovannetti E, Geldof AA, Avan A, Cavaletti $G$ and Peters GJ: Characterization of and protection from neurotoxicity induced by oxaliplatin, bortezomib and epothiloneB. Anticancer Res 34(1): 517-523, 2014.
Received August 4, 2018

Revised September 18, 2018

Accepted September 28, 2018 